\title{
OPTIMAL POWER FLOW USING STATCOM
}

\author{
Tanisha Bharol \\ Electrical and \\ Electronics \\ Department, \\ Bharati \\ Vidyapeeth \\ College of \\ Engineering, \\ New Delhi, India
}

\author{
Pranjali Bora \\ Electrical and \\ Electronics \\ Department, \\ Bharati \\ Vidyapeeth \\ College of \\ Engineering, \\ New Delhi, India
}

\author{
Sravani Sai M \\ Electrical and \\ Electronics \\ Department, \\ Bharati \\ Vidyapeeth \\ College of \\ Engineering, \\ New Delhi, India
}

\author{
Dhruvi Bansal \\ Electrical and \\ Electronics \\ Department, \\ Bharati \\ Vidyapeeth \\ College of \\ Engineering, \\ New Delhi, India
}

\author{
Dr. Sandeep \\ Sharma \\ Electrical and \\ Electronics \\ Department, \\ Bharati \\ Vidyapeeth \\ College of \\ Engineering, \\ New Delhi, India
}

\begin{abstract}
In power system, active power flow is the main concern in order to manage the demand supply. The maximum use of the transmission lines under their stability limit is very much required. Flexible alternating current transmission system (FACTS) device are very much useful to control power system parameters. A STATCOM (STATCOM) is a FACTS device which is able to control active and reactive power with voltage magnitude and phase angle. In this paper, STATCOM is used in a 10 bus system to control the flow of active power under contingency condition. Simulation result shows the effectiveness of the STATCOM in providing the optimal power flow in the power system considered here.
\end{abstract}

Keywords - STATCOM, optimal power flow, active power, reactive power.

\section{INTRODUCTION}

STATCOM can provide optimal power flow control is stated by Akagi et al (2008). In this paper, appropriate models are developed that can be integrated with the power flow algorithms. The modeling of STATCOM for the solution of optimal power flow (OPF) problem is explained by Bina et al (2008). The nonlinear equations are solved by Newton's method. A method to study optimal active power flow problem is developed by Villa Jaén et al (2008). This developed method considers the optimal power flow (OPF) problem as modified OPF. A paper presents solution of optimal power flow by Jovcic et al (2008). In this paper, a STATCOM implementation with its different control modes within the robust nonlinear interior-point OPF is done. A paper presents the use of STATCOM in restructured power system by Shah et al (2009). In this paper, a model of power flow studies incorporating a lossless model of STATCOM is presented. SVC and STATCOM modeling for longitudinal system to formulate the optimal power flow problem is done by Sternberger et al (2008). Sequential Quadratic programming technique is used for the solution of OPF problem. A paper formulates a nonlinear optimization problem using STATCOM to maximize the social welfare by Li et al (2008). In this paper, two step approaches is used for STATCOM for congestion management 1) the location of STATCOM, 2) proper setting of its control parameters. A linear programming (LP) based optimal power flow (OPF) algorithm is exhibited by Çetin et al (2008). This algorithm is used for STATCOM's corrective working and ease from overload and voltage violation due to system constraints. The objective is to minimize the load-ability of the heavily load lines. A screening technique is proposed in order to find the optimal location of STATCOM by Gupta et al (2009). This technique requires only one OPF to find the STATCOM parameter for transmission line. A method involving the optimization constraints of Newton method for finding the optimal reference input value for STATCOM for steady state operation is developed by Segundo-Ramírez et al (2009). This method is concerned with a high level line optimization control. STATCOM is explained for unbalanced condition is explained by Song et al (2009). The cascade multilevel and modular multilevel STATCOM is explained by Sternberger et al (2009) and Bina et al (2010) respectively.

The organization of this paper is done in following manner that MATLAB/Simulink model description is given in Section 2 whereas simulation results related to voltage, active power, and reactive power with STATCOM along different contingency condition of transformers are exhibited in section 3 in details. Section 4 represents the conclusion. 


\section{II.1 Electric power system model}

The system having two generating stations, ten buses, three transformers, four three phase loads, four different transmission lines and. This model (as shown in Figure 1) is simulated with STATCOM and results are recorded in

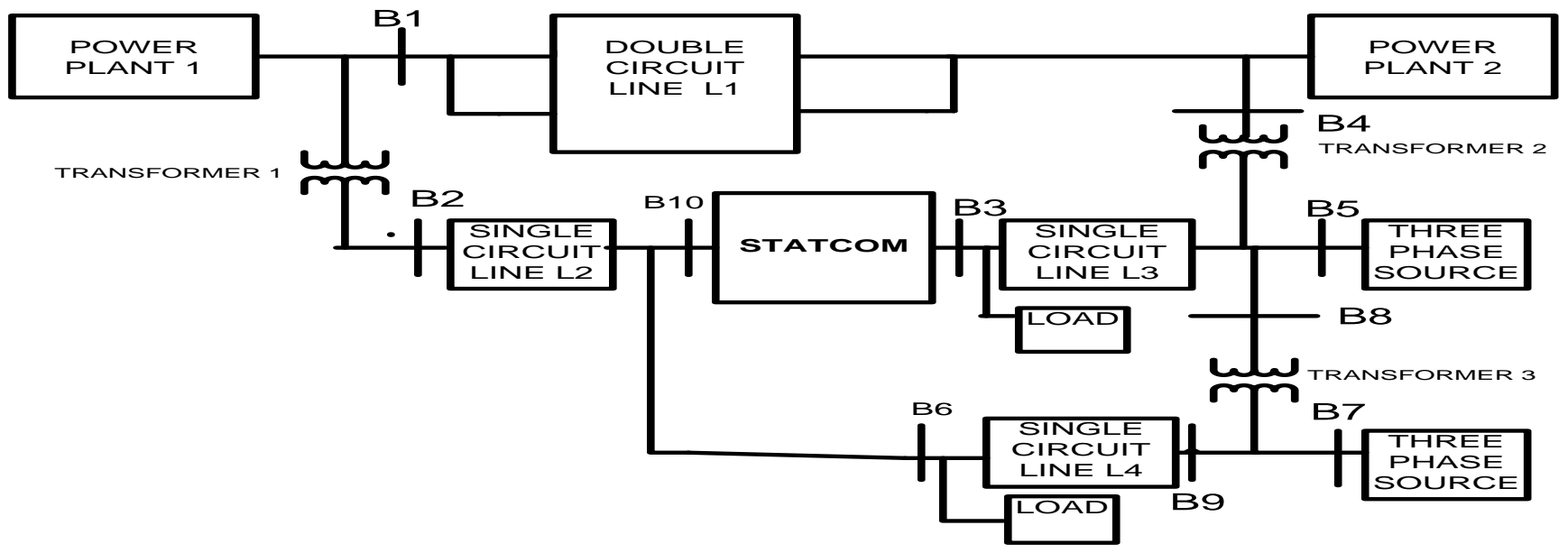

Figure1: Power system model with 10 bus system using STATCOM

This above simulation model is used to study the optimal power flow. Transformer 2 and Transformer 3 are taken into consideration. Transformer 1 and 2 are of capacity of
1200 MVA. Three unit of 400 MVA are considered for specification. Some contingency cases are taken into consideration for optimal power flow.

Table 1. Description of contingency cases for transformer 2 and transformer 3

\begin{tabular}{|c|c|c|}
\hline Contingency case & Rating of transformer 2 & Rating of transformer 3 \\
\hline Case 1 & $3 * 400$ MVA & $3 * 400$ MVA \\
\hline Case 2 & $3 * 400$ MVA & $2 * 400$ MVA \\
\hline Case 3 & $2 * 400$ MVA & $3 * 400$ MVA \\
\hline
\end{tabular}

III. SIMULATION RESULTS

The simulation result are taken for three different cases of the transformer 2 and transformer 3 . The result of each case in shown numerically.

\section{III.1 Case 1 when no transformer is out of service}

The simulation result for case 1 when no transformer is out of service, the simulation result are shown in table 2 and Fig. 2 to Fig. 7. The active power at B4 and B8 are $882.3 \mathrm{MW}$ and $580 \mathrm{MW}$ 
International Journal of Engineering Applied Sciences and Technology, 2021

Vol. 5, Issue 10, ISSN No. 2455-2143, Pages 265-269

Published Online February 2021 in IJEAST (http://www.ijeast.com)

Table 2. Voltage, active power, reactive power with STATCOM for case 1.

\begin{tabular}{|c|c|c|c|}
\hline & \multicolumn{3}{|c|}{ WITH STATCOM } \\
\hline BUS NO. & VPOS. SEQ. & $\begin{array}{c}\text { ACTIVE } \\
\text { POWER (MW) }\end{array}$ & $\begin{array}{c}\text { REACTIVE } \\
\text { POWER (MVAR) }\end{array}$ \\
\hline B1 & 0.9457 & 121.1 & -220.9 \\
\hline B2 & 0.9266 & 573.4 & 103.8 \\
\hline B3 & 0.9145 & 231.2 & 2522 \\
\hline B4 & 0.8771 & $\mathbf{8 8 2 . 3}$ & -3052 \\
\hline B5 & 0.7181 & 375.7 & -2306 \\
\hline B6 & 0.9145 & 325.2 & 1405 \\
\hline B7 & 1.089 & 642.5 & 5886 \\
\hline B8 & 1.561 & $\mathbf{5 8 0}$ & -2685 \\
\hline B9 & 1.089 & 146.2 & 0 \\
\hline B10 & 0.9145 & 0 & \\
\hline
\end{tabular}

III.2 Case 2 when one transformer of transformer three is out of service

The simulation result for case 2 when no transformer is out of service, the simulation result are shown in table 3 and Fig. 8 to Fig. 13. The active power at B4 and B8 are 891.5 MW and 464.1 MW.

Table 3. Voltage, active power, reactive power with STATCOM for case 2.

\begin{tabular}{|c|c|c|c|}
\hline & \multicolumn{3}{|c|}{ WITH STATCOM } \\
\hline BUS NO. & VPOS. SEQ. & ACTIVE POWER (MW) & REACTIVE POWER (MVAR) \\
\hline B1 & 0.955 & 94.07 & -187.1 \\
\hline B2 & 0.94 & 567.8 & 2146 \\
\hline B3 & 0.9303 & 202.5 & 989.6 \\
\hline B4 & 0.8972 & $\mathbf{8 7 1 . 5}$ & -2712 \\
\hline B5 & 0.7658 & 429.8 & -1955 \\
\hline B6 & 0.9303 & 359.7 & 1166 \\
\hline B7 & 1.075 & 514.5 & 5231 \\
\hline B8 & 1.665 & $\mathbf{4 6 4 . 1}$ & -2199 \\
\hline B9 & 1.075 & 154.5 & 0 \\
\hline B10 & 0.9303 & 0 & \\
\hline
\end{tabular}


International Journal of Engineering Applied Sciences and Technology, 2021

Vol. 5, Issue 10, ISSN No. 2455-2143, Pages 265-269

Published Online February 2021 in IJEAST (http://www.ijeast.com)

\section{III.3 Case 3 when one transformer of transformer 2 is out of service}

The simulation result for case 3 when no transformer is out of service, the simulation result are shown in table 3 and Fig. 14 to Fig. 19. The active power at $\mathrm{B} 4$ and $\mathrm{B} 8$ are $790.3 \mathrm{MW}$ and $546.8 \mathrm{MW}$.

Table 4. Voltage, active power, reactive power with STATCOM for case 3.

\begin{tabular}{|c|c|c|c|}
\hline & \multicolumn{3}{|c|}{ WITH STATCOM } \\
\hline BUS NO. & VPOS. SEQ. & ACTIVE POWER (MW) & REACTIVE POWER (MVAR) \\
\hline B1 & 0.9464 & 115.1 & 126.1 \\
\hline B2 & 0.9228 & 616.8 & 2522 \\
\hline B3 & 0.909 & 328.4 & 963.3 \\
\hline B4 & 0.8982 & $\mathbf{7 8 0 . 3}$ & -3097 \\
\hline B5 & 0.711 & 335.8 & -2295 \\
\hline B6 & 0.909 & 350.5 & 1308 \\
\hline B7 & 1.084 & 678.6 & 5706 \\
\hline B8 & 1.546 & $\mathbf{5 1 6 . 8}$ & -2677 \\
\hline B9 & 1.084 & 123.3 & 0 \\
\hline B10 & 0.909 & 0 & \\
\hline
\end{tabular}

\section{CONCLUSION}

STATCOM is a FACTS device which is able to control the power system parameters such as active and reactive power with voltage magnitude and phase angle. In this paper, STATCOM is used for an application of power system which is optimal power flow under contingency condition of transformers. In all the cases STATCOM shows its effectiveness in controlling the active power and achieving the optimal power flow on the buses B4 and B8. Hence STATCOM can be used for the flow of optimal power flow.

\section{REFRENCES}

[1] Akagi, H., Fujita, H., Yonetani, S. and Kondo, Y., (2008). A 6.6-kV transformerless STATCOM based on a five-level diode-clamped PWM converter: System design and experimentation of a 200-V 10-kVA laboratory model. IEEE Transactions on Industry applications, 44(2), (pp.672-680).

[2] Bina, M.T. and Bhat, A.K., (2008) Averaging technique for the modeling of STATCOM and active filters. IEEE Transactions on Power Electronics, 23(2), (pp.723-734)

[3] de la Villa Jaén, A., Acha, E. and Expósito, A.G., (2008) Voltage source converter modeling for power system state estimation: STATCOM and VSC-HVDC. IEEE Transactions on Power Systems, 23(4), (pp.1552-1559).

[4] Jovcic, D. and Sternberger, R., (2008). Frequencydomain analytical model for a cascaded multilevel STATCOM. IEEE transactions on power delivery, 23(4), (pp.2139-2147).

[5] Shah, N.M., Sood, V.K. and Ramachandran, V., (2009). Modeling, control and simulation of a chain link STATCOM in EMTP-RV. Electric power systems research, 79(3), (pp.474-483).

[6] Sternberger, R. and Jovcic, D., (2008). Theoretical framework for minimizing converter losses and 
harmonics in a multilevel STATCOM. IEEE

Transactions on Power Delivery, 23(4), (pp.23762384).

[7] $\mathrm{Li}, \mathrm{Y}$. and $\mathrm{Wu}, \mathrm{B} .,(2008)$. A novel DC voltage detection technique in the $\mathrm{CHB}$ inverter-based STATCOM. IEEE Transactions on Power Delivery, 23(3), (pp.1613-1619).

[8] Çetin, A. and Ermis, M., (2009). VSC-based DSTATCOM with selective harmonic elimination. IEEE Transactions on Industry Applications, 45(3), (pp.1000-1015).

[9] Gupta, R., Ghosh, A. and Joshi, A., (2009). Characteristic analysis for multisampled digital implementation of fixed-switching-frequency closed-loop modulation of voltage-source inverter. IEEE Transactions on industrial electronics, 56(7), (pp.2382-2392).

[10] Segundo-Ramírez, J. and Medina, A., (2009). Modeling of FACTS devices based on SPWM VSCs. IEEE Transactions on Power Delivery, 24(4), (pp.1815-1823).

[11] Song, Q. and Liu, W., (2009). Control of a cascade STATCOM with star configuration under unbalanced conditions. IEEE Transactions on Power Electronics, 24(1), (pp.45-58).

[12] Sternberger, R. and Jovcic, D., (2009). Analytical modeling of a square-wave-controlled cascaded multilevel STATCOM. IEEE Transactions on Power Delivery, 24(4), (pp.2261-2269).

[13] Bina, M.T., (2010). A transformerless mediumvoltage STATCOM topology based on extended modular multilevel converters. IEEE Transactions on Power Electronics, 26(5), (pp.1534-1545). 